\title{
One Size Does Not Fit All: Understanding User Preferences for Building Automation Systems
}

\author{
Simin Ahmadi-Karvigh ${ }^{\mathrm{a}}$, Ali Ghahramani ${ }^{\mathrm{b}}$, Burcin Becerik-Gerber ${ }^{\mathrm{c}}$, Lucio Soibelman ${ }^{\mathrm{d}}$ \\ ${ }^{a}$ Research Assistant, Sonny Astani Dept. of Civil and Environmental Engineering, Univ. of Southern California, \\ KAP 217, 3620 South Vermont Ave., Los Angeles, CA 90089-2531. E-mail: ahmadika@usc.edu \\ ${ }^{\mathrm{b}}$ Research Assistant, Sonny Astani Dept. of Civil and Environmental Engineering, Univ. of Southern California, \\ KAP 217, 3620 South Vermont Ave., Los Angeles, CA 90089-2531. E-mail: aghahram@usc.edu \\ ${ }^{\mathrm{c}}$ Associate Professor, Sonny Astani Dept. of Civil and Environmental Engineering, Univ. of Southern California, \\ KAP 224C, 3620 South Vermont Ave., Los Angeles, CA 90089-2531. E-mail: becerik@usc.edu \\ ${ }^{d}$ Professor, Sonny Astani Dept. of Civil and Environmental Engineering, Univ. of Southern California, KAP 210A, \\ 3620 South Vermont Ave., Los Angeles, CA 90089-2531. E-mail: soibelman@usc.edu
}

\begin{abstract}
:
In recent years, technological advances have substantially extended the capabilities of automation systems in buildings. Despite the achieved advances, automation systems have not been widely adopted by building occupants. This paper presents ourinvestigations onautomation preferences of occupants for the control of lighting systems and appliancesin residential buildings. A survey was carried out to determinehow preferences for level of automation vary by contexts as well asindividuals' personalities and demographic characteristics. The contexts investigated in this study include rescheduling an energy consuming activity, activity-based appliance state control,and lighting control. The collected data from 250 respondents wereanalyzed using Generalized Linear Mixed Models. Based on the results,an automation level with higher user participation is more preferredfor rescheduling an activity. For control ofactivity-based appliance states and lighting,levels of automation with lower user participation are more preferred. Our findings also indicate that income and education levels and alsopersonality traits of agreeableness, neuroticism and openness to experience affect the preference of particular automation levels over the others. Findings from this study can be used in designing user-centered automation systems that lead to potentially more satisfying operation and hence, couldenhance automation acceptability.
\end{abstract}

Keywords:Energy Efficiency; Adjustable autonomy; Occupant preferences; Appliance control; Lighting control; Automation

\section{INTRODUCTION}

Buildings account for more than $40 \%$ of total energy consumption and $70 \%$ of total electricity consumption in the United States [1]. The significant contribution of buildings in consuming limited sources of energy on Earth has ignited a growing worldwide interest to improve energy efficiency via automating the operations of energy consuming service systems. Despite the achievements in this area, building automation has not been widely adopted by buildingoccupants[2, 3]. Consequently, this ongoing issue still challenges researchers to find more effective paradigms to design adoptable building automation systems that do not solely rely on technological capabilities or economic benefits[4].

In complex systems with several interacting components, such as buildings, in order to efficiently achieve an operational goal (e.g., improving building energy efficiency), a set of functionsneed to be carried out. 
These functions can be categorized into two classes of input functions and output functions[5]. Input functions refer to the functions for data acquisition and data analysis. Given a building equipped with a sensing system, data acquisition functions are carried out to obtain information about occupants and physicalenvironments within abuilding (e.g., an occupant's location in the room, energy consumption of appliances andlight intensity in the room)[6-8]. Relying on the obtained information, data analysis functions are performedto discoverknowledge required to precede the output functions. Occupant activity and preference recognition, wasted energy consumption detection and behavior prediction are examples of data analysis functions[9-11]. Output functions include the functions for action selection (decision making) and action implementation. Action selection functions involve selecting an action among the available options. A building-related example is a case where the lights in a room are on and the room is not occupied. In this situation, decision making function could be the selection between turning off the lights and leaving them on. Consistent with the decisions, the functions in action implementation are the actual execution of the chosen actions. Accordingly, for the previously given example, if the choice of the action is to turn off the lights, the action implementation function is to accomplish the action (i.e., turning off the lights).

60

61

62

63

64

65

66

67

68

Due to recent technological advancements, building automation systemsare now capable of performing many of these functions autonomously. However, research has shown that even if technological capabilities allow, fully automating all of these functions does not always lead to the most satisfactory operations [5, 12]. An alternative solution is to harmonize the automation level with the workloadneeded for thefunctions (i.e., amount of work required to perform the functions) [13]. This implies that rather than having extreme cases of fully automated or fully manual conditions only, depending on the function's workload, various levels of automation, ranging from zero to full automation, can be assigned to each function[14]. This is called adjustable autonomy [15]. The workload of a functiondepends on the context, in which the function is performed (e.g., the context of controlling the lighting system). Tailoring the level of automation to match the workload offers the opportunity to increase user control over the system and simultaneously avoid user inconvenience by imposing more participation in the contexts with lower levels of workload. This would potentiallylead to less error-prone operations and hence, couldenhance automation acceptability.

In addition to the workload,in order to determine the appropriate level of automation, subjective factors that causeindividual differences in response to automation should be also considered[16]. In general, human interactions with other human or nonhuman agentshave shown to be affected by both general trust and context dependent trust, which are two dimensions of interpersonal trust [17, 18]. While general trust is part of one's personality and hence is affected by personality traits, context dependent trust is related to prior similar experiences. As a result, in unfamiliar situations, general trust exerts more impact on an individual's behavior, whereas in unfamiliar situations, context dependent trust is more influential.Accordingly, a combination of impacts from one's personality traits and previous automation experiences affect a user's response to automation.Evidence in support of this contention isprovided by studies demonstrating the effect ofuser's personality traits or demographic-related characteristicsonuse of a technology (e.g., adoption of technology in households [19], use of communication tools by students [20], and acceptance of mobile commerce [21]).

Following the concept of adjustable autonomy,the procedure for automation design in a system should involve determination of the level of automation needed for different functions.The context in which a function is performed, and also individual's characteristics together contribute to formation of the preference for the automation level, based on which the appropriate level of automation needed for different functions could be determined. With the purpose of incorporating automation preferences into the process of automation design, investigations on automation preferences have been conducted in several domains, such as aircraft control[12]. However, there still exists a gap for understanding the variation of automation preferences among the individuals in the application of building energy 
efficiency. Accordingly, in order to address the described gap in automation design for buildings, we have investigated occupants' automation preferences to control the operation of buildings' energy consuming service systems. In particular, in this paper, our focus is residential buildings, which consume electricity slightly more than commercial buildings (i.e., 51\% versus 49\%)[22, 23]. Among the energy consuming service systems, we selectedlighting systems and appliances, as these systems together contribute to considerable portion of the electricity consumption in residential buildings (i.e., 55\%)[22]. To investigate automation preferences, we conducted an online survey, in which the respondents were presented with different automation scenariosthatrepresented different automation levels. These scenarios were presented for various contexts, including rescheduling an energy consuming activity, activity-based management of different appliance states, and control of lighting systems. In addition to the context, individual differences also affect automation preferences. Accordingly, we also explored the effect of respondents' personality traits (i.e.,extraversion, agreeableness, conscientiousness, neuroticism and openness to experience) and demographic related characteristics (age, gender, marital status, education level and income) on automation preferences. Following the summary of related studies and research questions presented in section two, the details of our proposed methodology are provided in section three. Next, the results and discussion are presented in section four and five, respectively. Limitations of the study and potential future work are presented in section six and section seven concludes the paper.

\section{LITERATURE REVIEW}

In recent years, technological advances have substantially extended the capabilities of automation systems in buildings [24-26]. Despite the achieved advances, automation systems have not been widely adopted by building occupants. An evidence of this problem is presented in a study carried out in 40 offices, during 5 months, where the results indicated that the majority of the occupants were not satisfied with the automation system and hence, they stopped using it [27]. In order to understand the barriers the authors of $[27,28]$ carried out home visits to 14 residential units, which used automation, and found that inflexibility, poor manageability and difficulty in achieving trust were the main reasons behind occupant dissatisfaction. Other investigations, based on the experiences of families living in smart houses, have revealed that occupant dissatisfaction could significantly decrease when more control over the execution of the functions is offered to the users [29, 30]. Accordingly, researchers have proposed adjustable autonomy, where various levels of automation (ranging from zero to full) is provided in different contexts, in order to increase user control over the automation system[15]. Along this line, the authors of [31] suggested a novel approach to provide adjustable autonomy, where decision making was occasionally transferred to the user. In another study, an adaptive automation system that gradually could become autonomous by learning user preferences was proposed to control appliances in a hospital room [32]. More recently, agent-based approaches also were used to provide adjustable autonomy in buildings to increase energy efficiency[33, 34].

Since in adjustable autonomy, automation level is altered to match the automation needed in different contexts, the procedure of automation design should involve determination of user automation preferences. In a study by Parasuraman et. al., pilots performing monitoring a task in a simulated flight were offered with three option of automation matched with the workload, automation poorly matched with the workload, and no automation[12]. Among the provided options, workload-matched automation was the most preferred option and resulted in the best monitoring performance. In another study carried out on terrorist threat detection in a simulated environment, the effects of personality and task (equivalent to context in our study) on userresponse to automation (in terms of user performance and stress level) were investigated[16]. Findings of this study indicated that the variable of task had stronger influence on automation response than the variable of personality did. The study also showed that automation response to a particular task was not always common across individuals, due to personality-related effects. These effects found to be mainly negative for neuroticism, as opposed to other personal traits, such asextraversion and agreeableness, for which positive effects were generally reported. 
There are also studies conducted on user automation preferences for automation in buildings. Along this line, Ball et al., carried out a survey to assess university students'automation preferencesto control different services in a smart home(i.e., controlling doors and windows, monitoring energy usage, automatic indoorheating, automatic room lighting, and providing entertainment services such as choosingmovies)[35]. The survey results revealed the usefulness of adjustable autonomy, asparticipants' automation preferenceswere found to be different across the services (equivalent to context in our study). In another study, the authors have presented the results of an empirical study conducted in six different sites, where the participants were asked questions regarding the explained automation scenarios of intelligent entertainment systems (e.g., playing and finding movies, music and games, and adjusting light and sounds in a room for movie watching or game playing); and intelligent home caring systems (e.g., controlling the doors, finding cooking recipes, and detecting faults in operation of a washing machine) [36]. The study showed that users would prefer an automation system that is easy to use and configurable to accommodate individual settings and preferences.

159

160

161

162

163

164

165

166

167

168

169

170

171

172

173

174

175

176

177

178

179

180

181

182

183

184

185

186

187

188

189

190

191

192

193

194

195

Among the studies on user preferences for automation in buildings, there are number of studiesthat carried out their investigations with particular focus ofenergy efficiency. These studies either exploreduserpreferences on the type of feedback they wanted to receive from an automation system regarding their energy consumption, e.g., aggregated electricity consumption vs. disaggregated appliancelevel electricity consumption[37-39]; or studied samples that were not large enough to derivegeneralizable knowledge. For example, findings of a pilot study with 26 participants on user satisfaction level associated with different control strategies of dynamic façades indicated that increasing the user control over the façade automation via offering the opportunity to manually override the commandsled to significantly higher satisfaction levels [40].In another study, the authors of [41] conducted a scenario-based study to investigate automation preferences with regards to three contexts, i.e., control of indoor thermal environment, peak load management, and onsite energy production, using the data from qualitative interviewswithonly 14 participants. The study showed that full automation was not a preferable option for automating functionsrelated to indoor thermal control. In addition, substantial mistrust on automation was reported, which could potentially be decreased by carefully choosing the automation level.In summary, existing studies on user automation preferences in buildings does not cover the contexts associated with different automation strategies related to energy efficiency of appliances and lighting systems.Moreover, neither of these studies has investigated the effects of individual's characteristics, in terms of both demographics and personality, on automation preferencesin these contexts.

\section{METHODOLOGY}

In order to address the stated gap in literature, in this study, we have investigated the effects of contexts and individual differences on automation preferences for appliances and lighting systems control in residential buildings. To achieve the stated objective, the following research questions were sought to be answered:

- How do automation preferences for lighting and appliancecontrol for an occupant vary in different contexts?

- How do automation preferences for lighting and appliancecontrol vary by occupant demographics (i.e., age, gender, marital status, education level, and income)and personalities traits (i.e., extraversion, agreeableness, conscientiousness, neuroticism and openness to experience)?

In order to answer the stated research questions, we carried out a quantitative study by conducting an online survey. Below is a description of our methodology.

\subsection{Questionnaire Design}


Wefirst determined our dependent and independent variables with regards to our research questions. Based on our explanation provided in the previous sections with regards to the literature, three main groups of independent variables, i.e., demographics, personality and context, and one dependent variable, i.e., automation level, were defined. For demographics as a categorical variable, we considered age, gender, marital status, education level, and income level. These five variables were identified based on extensive literature review of the factors that impact new technology acceptability, which can be found in section 2. For the variable of personality, we used the Big Five personality traitsas standard representations of personality dimensions[42].These traitsinclude extraversion, agreeableness, conscientiousness, neuroticism and openness to experience. Extraversion is a measure of sociability, such that people with high scores tend to enjoy company of others, whereas those with low score appreciate being alone more. Agreeableness measures one's trusting nature and tendency of being sympathetic. Accordingly, people with high scores are generally forgiving and compassionate, while those with low scores are critical and suspicious. Conscientiousness measures how well aperson is organized, such that those with high scores are self-disciplined and careful, while ones with low scores are disorganized. Neuroticism measures the tendency to be anxious about things. People with high neuroticism are nervous and tend to worry about things, but, in contrast, those with low scores are calm and relaxed. Finally, openness to experience is a measure of creativity and curiosity, such that those with high scores are not conservative and always seek new experiences, whereas the ones with low scores are conventional and uncreative.

To define the context as a variable, we focused on the activities that involve use of appliances and lighting systems (making up more than half of electricity use in buildings) and the associated automation strategies that intend to improve energy efficiency of these service systems, with respect to occupant needs. For appliances, the automation strategies can be categorized into three main groups. The first group are the strategies that aim atperforming load control for peak electricity use periods. During the peak demand hours, utilities generally face difficulties in providing additional capacity and hence they try to reduce the demand by shifting electricity-using activities from peak hours to non-peak hours (i.e., demand response). To encourage users to postpone their activities to non-peak hours, several utility providers have been offering non-flat electricity rates, i.e., higher prices during peak demand hours and lower prices at other times[43]. Asresidential end uses have shown to significantly contribute to the electricity peak demand[44], we defined the first two contexts as rescheduling activity of using a dishwasher and rescheduling activity of using a washer and a dryer. Another group of automation strategies to improve energy efficiency of appliances are those which control appliancestandby power. Standby power is the electricity used by appliances while they are not on but still plugged-in. 5 to $10 \%$ ofthe electricity consumption in residential buildings is consumed by standby power[45]. Accordingly, the third context in our questionnaire was defined as appliance standby power control. The last group of automation strategies are those that controls the unneeded appliances that are left on. These approaches have applications both in safety, e.g., turning off an unneeded iron, and electricity saving, e.g., turning off the computers when they are not in use [46]. Consequently, the fourth context was defined as turning off the unneeded left on appliances.For lighting systems, previous studies have shown that occupancy-based lighting system control can save up to $30 \%$ of lighting electricity consumption [47]. Accordingly, the fifth context in our questionnaire was defined as turning off the unneeded left on lights.

As explained before, contexts involve a set of decision making and action implementation functions (i.e., output functions). These functionscan be fully or partially automated. In agreement with this explanation, for our dependent variable (i.e., automation level), we defined two extreme cases of full automation and no automation. In full automation, both decision making and action implementation functions are fully assigned to the automation system andhence, zerouser participation is required. In contrast, in no automation, there is zero level of automation and hence, all functions are executed manually. Theoretically, from full to zero, the level of automationcan be altered in a continuous range. As depicted in Figure 1, user participation increases asthe level of automation decreases.Accordingly, in between the 
two extreme cases of full and no automation, we defined two levels of automation: inquisitive automation amount ofautomation, as opposed to the latter, which is in the region with theloweramount of user participation than the amount of automation. In inquisitive automation, automation system always asks for occupant permission before taking any action. In other words, based onthe decision making function, which is always manual for inquisitive automation, action implementation function could be either manual or automated depending on occupant decisions. On the other hand, in adaptive automation, automation system learns occupant needs and patterns in time by occasionally getting feedback from the occupant. This implies that decision making function in adaptive automation is partially manual and hence, level of automation for action implementation is also higher than its level in inquisitive automation.It should be pointed out here that although between full and no automation, more than two levels of automation could be defined. In order to avoid user confusion in differentiating the condition of giving more control to the automation system versus the condition in which user has more control, we limited our investigations to the suggested two levels.

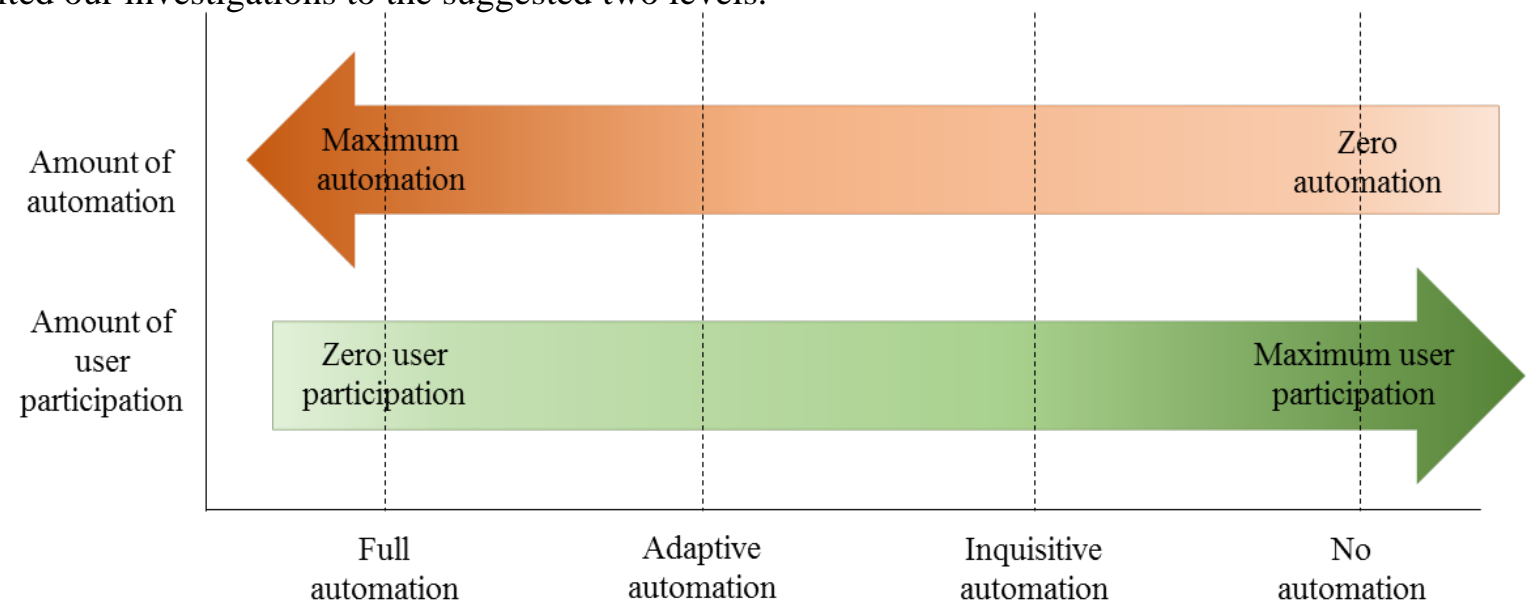

Figure 1. Comparison of different automation levelsin terms of amount of automation and user participation

As there were already existing standard questions for measurements of demographics and personality traits[42], our main challenge in designing the questionnaire was to find an approach to well explain the third independent variable, i.e., context, and our only dependent variable, i.e., automation level. Due to the complexity of these concepts, prior to asking any questions, we first introduced the concepts using descriptive animated videos ${ }^{1}$. In each video, we presented a short explanation of a given context, along with the possible scenarios for different automation levels. To assure the respondenthas watched the videos and understood the concepts before answering the questions, we designed trap questions in addition to our main questions at the end of each video. These trap questions required specific answers that could be selected if the respondentcarefully watched the videos.

Following the questionnairedesign, in order to evaluate the appropriateness, clarity and validity of the questions and choices, we first pre-tested our survey by conducting a pilot study with several iterations, using the online platform of Qualtrics. When the respondents responded to the survey in our pilot testing, they were asked to provide us with the feedback regarding the videos, questions and also the user interface for the survey. Based on the feedback, we revised and finalized the questionnaire.

\footnotetext{
${ }^{1}$ https://www.youtube.com/playlist?list=PLJxJX4lDIs9vQEjHBIWLVoVubMmZmzCgV
} 


\subsection{Data Collection}

Once the questionnaire was finalized, we conducted our data collection by distributing the survey via the online platform of Amazon Mechanical Turk.This platform has been heavily used in several domains (e.g., computer science,psychology and other social sciences) to obtain high-quality data inexpensively and rapidly[48].In order to ensure there was no multiplicity in the responses, we checked the uniqueness of the IP addresses to avoid multiple participations. All of the respondents were randomly selected from users of Amazon Mechanical Turk who were 18 years old or above and were residents of the United States.Respondents were given a small amount of monitory reward for their participation in the survey. The survey was open during 2 months and total of 250 valid responses were collected. The validity of a response was ensured based on the answers of the respondent to the designed trap questions explained in section 3.1. As these questions required specific answers, the data associated with invalid responses were discarded.Based on a general rule, for logistic regression-based analysis, which is explained in next section,more than 10 observations per degree of freedom is required[49]. Based on our variables (Table 1 ), the degree of freedom in our study is 19 . Hence, 250 responses satisfy the stated rule.

\subsection{Statistical Analysis}

The collected survey data werefirst cleanedbased on validity of the respondents and coded to get ready for statistical analysis. The software we used to perform our analysis was SPSS version 24.0. For the statistical analysis, we ran a set of descriptive and inferential analyses. Descriptive analysis provided us with a high level of insight on the data and distribution of the responses, whilethe inferential analysis offered an estimation of the variables' effects on the outcome.The appropriate inferential analysis technique was selectedbased on the type of variables and the data characteristics. Table 1 presents variable definitions and types. Since investigated variables in this study were all categorical (either nominal or ordinal), some of the well-established approaches, such as ANOVA that are suitable for continuous variables, could not be used here[50, 51]. Instead, we used a logistic regression-based approach (i.e., Generalized Linear Mixed Model).

\begin{tabular}{|c|c|c|c|}
\hline $\begin{array}{c}\text { Variable } \\
\text { type }\end{array}$ & Variable name & Data type & Possible values \\
\hline \multirow{10}{*}{$\begin{array}{l}\text { Independ } \\
\text { ent } \\
\text { variables }\end{array}$} & Age & $\begin{array}{l}\text { Categorical - } \\
\text { Ordinal } \\
\end{array}$ & $\begin{array}{l}=<32 \text { years old, } 33 \text { to } 47 \text { years old, }>=48 \text { years } \\
\text { old }\end{array}$ \\
\hline & Gender & $\begin{array}{c}\text { Categorical - } \\
\text { Nominal } \\
\end{array}$ & Male, Female \\
\hline & Marital status & $\begin{array}{l}\text { Categorical - } \\
\text { Nominal }\end{array}$ & Single, Married \\
\hline & Education level & $\begin{array}{l}\text { Categorical - } \\
\text { Ordinal }\end{array}$ & $\begin{array}{l}\text { Less than Bachelor's degree, Bachelor's degree, } \\
\text { Master's degree and Doctorate }\end{array}$ \\
\hline & Income level & $\begin{array}{l}\text { Categorical - } \\
\text { Ordinal }\end{array}$ & $\begin{array}{l}=<40,000 \text { (Lower than average), } 40,001 \text { to } \\
69,999 \text { (Average), }>=70,000 \text { (Higher than } \\
\text { average) }\end{array}$ \\
\hline & Extraversion & $\begin{array}{l}\text { Categorical - } \\
\text { Ordinal }\end{array}$ & \multirow{5}{*}{$\begin{array}{l}\text { Lower than average, Average, Higher than } \\
\text { average }\end{array}$} \\
\hline & Agreeableness & $\begin{array}{l}\text { Categorical - } \\
\text { Ordinal }\end{array}$ & \\
\hline & Conscientiousness & $\begin{array}{l}\text { Categorical - } \\
\text { Ordinal }\end{array}$ & \\
\hline & Neuroticism & $\begin{array}{l}\text { Categorical - } \\
\text { Ordinal } \\
\end{array}$ & \\
\hline & $\begin{array}{l}\text { Openness to } \\
\text { experience }\end{array}$ & $\begin{array}{l}\text { Categorical - } \\
\text { Ordinal } \\
\end{array}$ & \\
\hline
\end{tabular}




\begin{tabular}{|c|c|c|l|} 
& Context & $\begin{array}{c}\text { Categorical }- \\
\text { Nominal }\end{array}$ & $\begin{array}{l}\text { Rescheduling an activity (dishwasher), } \\
\text { Rescheduling an activity (washer and dryer), } \\
\text { Managing standby power, Turning off unneeded } \\
\text { appliance, Turning off unneeded lights }\end{array}$ \\
\hline $\begin{array}{l}\text { Dependen } \\
\text { t variable }\end{array}$ & Automation level & $\begin{array}{c}\text { Categorical - } \\
\text { Nominal }\end{array}$ & $\begin{array}{l}\text { Full automation, Adaptive automation, } \\
\text { Inquisitive automation, No automation }\end{array}$ \\
\hline
\end{tabular}

Table 1. Characteristics of the variables used in this study

Logistic regression is a special case of generalized linear model, which itself is categorized as type of regression analysis. The math behind logistic regression is underlain by odds ratio such that log of the odds is expressed by linear combination of independent variables (Equation 1).

$\log \left(\frac{\pi_{c}}{\pi_{r}}\right)=\alpha+\beta_{1} x_{1}+\beta_{2} x_{2}+\beta_{3} x_{3}+\cdots+\beta_{k} x_{k}$ Equation 1

In Equation 1, $\frac{\pi_{c}}{\pi_{r}}$ is the oddsof outcomec over outcome $r, \alpha$ is intercept of the model, and $\beta_{i}$ is the coefficient of independent dummy variable $x_{i}$ (it can take values of either 1 or 0 ), which is known as a fixed effect.

We hadfour possible values for the dependent variable (see Table 1). There arosethe need to use multinomial logistic regression, which generalizes logistic regression for multiclass cases. Multinomial logistic regression is a generalized linear model where the outcome has multinomial distribution and the link function is logit. Given that there aren possible values for the dependent variable, multinomial logistic regression proceeds by fitting $n-1$ separate binary logistic models (Equation 1 ) to comparethe category $c$ with a baseline category $r$ known as reference category. In each model, if the log odds ratio is positive the probability of the category $c$ will be higher than reference category and if it is negative the probability of reference category will be higher. Accordingly, the positive coefficients in each model are in favor of increasing the probability of categoryc, whereas negative ones are in favor of increasing the probability of the reference category. As mentioned before, the fixed effects in models must be encoded to dummy variables. Therefore, given that there are $m$ distinctive possible values for an independent variable, there is a need for $m-1$ coefficients for that particular encoded dummy variable in each binary model.

As we took multiple measures per subject, i.e., each measure for one context, our responses were not independent. Toresolve the dependency of the observations,we used an extension of multinomial linear logistic regression, called Generalized Linear Mixed Model (GLMM)[52].The advantage of GLMM over logistic regression is that in addition to the fixed effects, it is capable of accounting for random effects and hence it is a suitable approach for repeated measures. In the GLMM, random effects are modeled by assuming random intercepts that is, each subject is assigned a different intercept but similar coefficients. We initially fitted the GLMM with all independent variables as fixed effects and individual's identity (anonymous, unique ID number) as the random effect. We fitted a simpler GLMM with same random effect by progressively deleting the non-significant fixed effects until all remaining fixed effects were significant.Comparisons between modelswere carried out usingAkaike Information Criterion (AIC), which is a relative measure for model comparison based on log-likelihood [53]. Models with lower AICs are preferred, as they suggest better model fit. In order to test the significance of the fixed effects in the model selection, we used type III F-test, also known as the fixed effect test. In type III F-test, for a given fixed effect, the null hypothesis tests if the coefficients associated with that effect are zero. In case the effect is categorical with more than two levels, several coefficients are associated with the effect. Hence, 
the null hypothesis tests whether all these coefficients are zero. If the p-value, i.e., probability of the null hypothesis being true,isless than the critical significance level, i.e., 0.05, the null hypothesis gets rejected with 95\% confidence level and it can be concluded that the fixed effect contributes to the model by affecting the outcome.

Since we had multilevel dependent variable, the final selected GLMM was a combination of binary models. We used t-test to evaluate the significance of different levels of the fixed effects in binary models. In t-test, for a given level of a fixed effect,in an estimated binary model, i.e., $x_{i}$, the null hypothesis test whether the associated coefficient, i.e., $\beta_{i}$, is zero. In case the p-value is less than 0.05 , the null hypothesis gets rejected.

\section{RESULTS}

In our sample, about $53 \%$ were male and $47 \%$ were female. About $45 \%$ of the sample were 32 years old or younger, 35\% were between 33 and 47 years old, and 20\% were 48 years old or older. The majority of respondents, i.e., about $70 \%$, was single and $30 \%$ were married. Finally, about $22 \%$ of the respondentswere holding less than a Bachelor's degree, 47\%were holding (or were currently enrolled in) a Bachelor's degree, and 31\% were holding(or were currently enrolled in) a Master's degree or Doctorate.

We first carried out a set of descriptive analyses to obtain a high-level insight on the data. Along this line, we explored the measure of data dispersion via attaining percentage of respondents in each group of automation preference for different contexts (Figure 2).

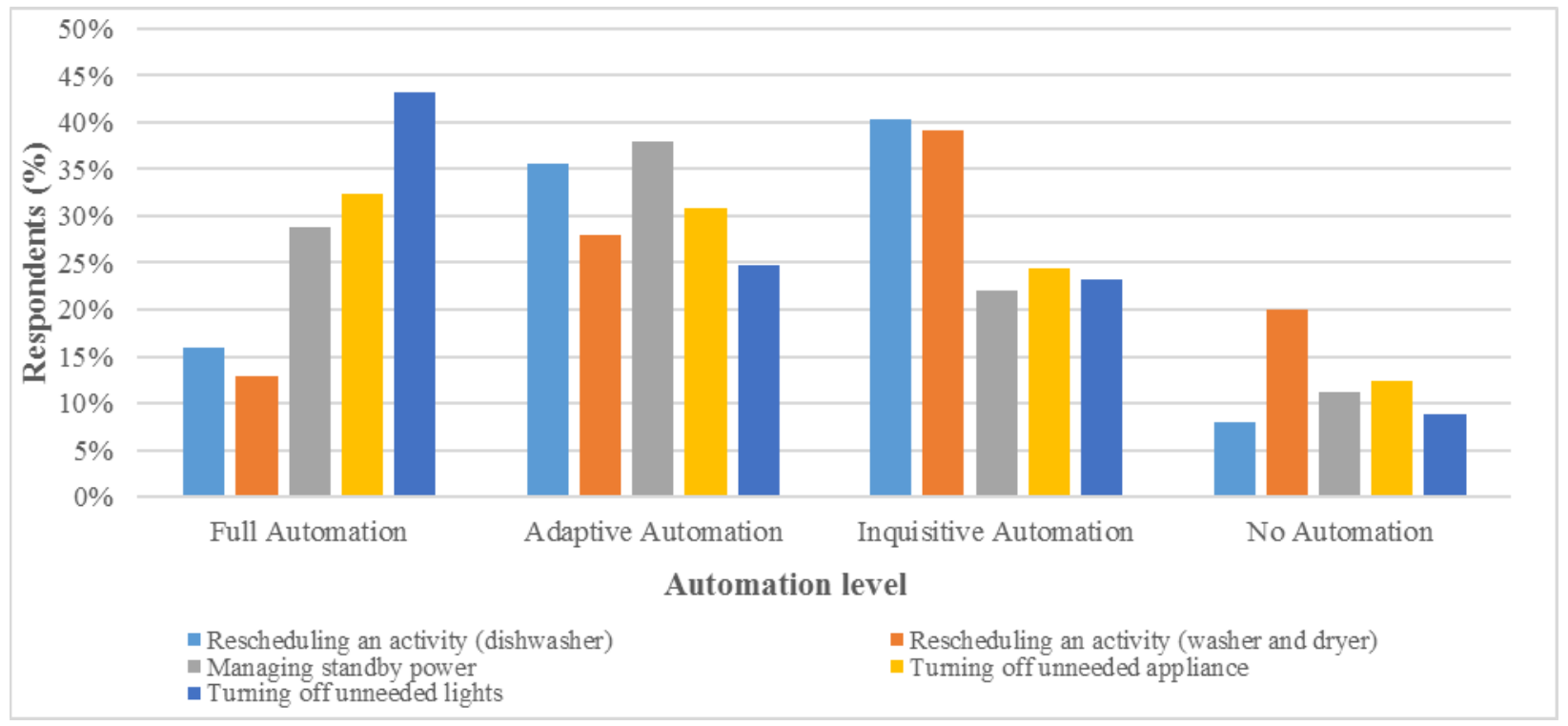

Figure 2. Distribution of respondents in each group of preferred automation level for different contexts

Figure 2 suggests thatno automation is the least preferred option by the respondents. To confirm the significance of this statement, inFigure 3, we present the cumulative distribution of responses in each group of automation preferences, along with their 95\% Confidence Intervals (CIs), which are depicted by the error bars[54]. It can be seen that the upper bound of CIs for no automation is lower than $25 \%$, which would be the percentage of preferring an option in case of a random selection. In addition, the CIs of no automation do not overlap with the CIs of other automation levels. Accordingly, with $95 \%$ confidence, it can be concluded that no automation is the least preferred option compared to other automation levels. 


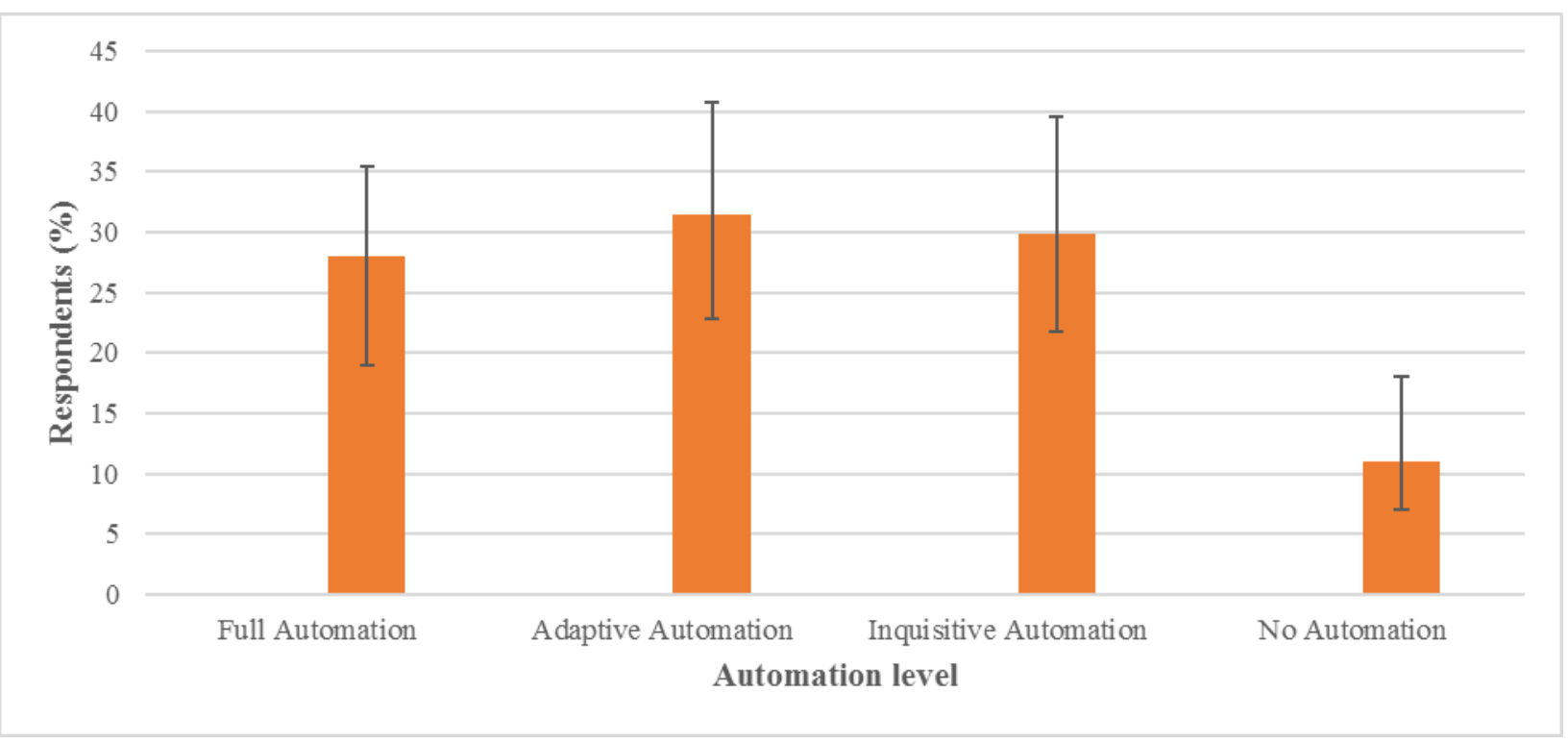

Figure 3. Cumulative distribution of respondents in each group of preferred automation level

For the inferential analysis, we explored the effects of the independent variables on our dependent variable by constructing GLMMs. Except for no automation, which was selected by considerably smaller number of respondents, either of the three automation levels, i.e., full automation, adaptive automation and inquisitive automation, could be an adequate choice for a reference category, as they were selected with close frequency in total. Accordingly, we constructed three GLMMs with each of the three automation types as the reference category. Based on the previous explanations, we first fitted the GLMMs with all independent variables and iteratively simplified the models. Table 2 summarizes the results of the performed model selection, via presenting the F-values and p-values. In calculating Fvalues,the requireddegrees of freedom were estimated using Satterthwaite approximation method [52]. As shown in table 2, we achieved the final GLMM for each reference category in 2 iterations. The final models(i.e., GLMM 2 - F (for reference category of full automation), GLMM 2 - A (for reference category of adaptive automation), and GLMM 2 - I (for reference category of inquisitive automation)) have lower AIC compared to the previous models (i.e., GLMM 1 - F, GLMM 1 - A, and GLMM 1 - I). Moreover, they only contain fixed effects that are significant (p-value $<=0.05$ ). The final modelsconfirm that among the demographic-related variables, income and education level is significant, andamong the personality-related variables, agreeableness, neuroticism and openness, are significant.

\begin{tabular}{|c|c|c|c|c|c|c|c|c|c|c|c|c|}
\hline $\begin{array}{l}\text { Reference } \\
\text { Category }\end{array}$ & \multicolumn{4}{|c|}{ Full automation (F) } & \multicolumn{4}{|c|}{ Adaptive automation (A) } & \multicolumn{4}{|c|}{ Inquisitive automation (I) } \\
\hline Model & \multicolumn{2}{|c|}{ GLMM 1-F } & \multicolumn{2}{|c|}{${\text { GLMM } 2-F^{a}}^{a}$} & \multicolumn{2}{|c|}{ GLMM 1-A } & \multicolumn{2}{|c|}{ GLMM 2-A $^{a}$} & \multicolumn{2}{|c|}{ GLMM 1-I } & \multicolumn{2}{|c|}{ GLMM 2-I $^{a}$} \\
\hline Variable & F-value & $\mathrm{p}$-value & F-value & p-value & F-value & $\mathrm{p}$-value & F-value & p-value & F-value & $\mathrm{p}$-value & F-value & $\mathrm{p}$-value \\
\hline Intercept & 3.766 & $0.000^{*}$ & 5.039 & $0.000^{*}$ & 3.932 & $0.000^{*}$ & 5.955 & $0.000^{*}$ & 3.752 & $0.000^{*}$ & 5.667 & $0.000^{*}$ \\
\hline Age & & & - & - & & & - & - & & & - & - \\
\hline Gender & 1.594 & 0.190 & - & - & 1.794 & 0.148 & - & - & 2.311 & 0.076 & - & - \\
\hline Marital status & 2.137 & 0.095 & - & - & 2.593 & 0.052 & - & - & 1.909 & 0.127 & - & - \\
\hline Education level & 2.420 & $0.026^{*}$ & 2.215 & $0.041^{*}$ & 1.665 & 0.128 & - & - & 1.646 & 0.133 & - & - \\
\hline Income level & 4.089 & $0.001^{*}$ & 4.491 & $0.000^{*}$ & 4.918 & $0.000^{*}$ & 5.347 & $0.000^{*}$ & 3.462 & $0.002 *$ & 3.726 & $0.001^{*}$ \\
\hline
\end{tabular}




\begin{tabular}{l|cc|cc|cc|cc|cc|cc} 
Extraversion & 1.224 & 0.293 & - & - & 0.819 & 0.556 & - & - & 0.832 & 0.545 & - & - \\
Agreeableness & 3.455 & $0.002 *$ & 3.581 & $0.002^{*}$ & 4.176 & $0.000^{*}$ & 4.108 & $0.001^{*}$ & 3.568 & $0.002^{*}$ & 3.890 & $0.001^{*}$ \\
Conscientiousness & 0.699 & 0.650 & - & - & 0.648 & 0.692 & - & - & 0.664 & 0.679 & - & - \\
Neuroticism & 2.430 & $0.025^{*}$ & 2.982 & $0.007^{*}$ & 2.134 & $0.049^{*}$ & 2.449 & $0.024^{*}$ & 2.120 & $0.050^{*}$ & 2.795 & $0.011^{*}$ \\
$\begin{array}{l}\text { Openness to } \\
\text { experience }\end{array}$ & 2.961 & $0.008^{*}$ & 3.265 & $0.004^{*}$ & 2.911 & $0.009^{*}$ & 3.036 & $0.006^{*}$ & 2.632 & $0.016^{*}$ & 2.767 & $0.012^{*}$ \\
Context & 10.910 & $0.000^{*}$ & 10.742 & $0.000^{*}$ & 11.601 & $0.000^{*}$ & 11.389 & $0.000^{*}$ & 11.342 & $0.000^{*}$ & 11.131 & $0.000^{*}$ \\
\hline \hline \multicolumn{1}{c|}{ AIC } & 14922 & 14548 & 15008 & 14576 & 15018 & 14591 \\
\hline
\end{tabular}

Table 2. Results of type III F-testsand computed AICs forbuilt GLMMs during model selection.

$392 \quad{ }^{\mathrm{a}}$ Final selected model.

$393 *$ Significant variables ( $\mathrm{p}$-value $<=0.05)$.

Table 3presents the GLMM coefficients for the fixed effects along with the associated results of conducted t-tests. As explained before, in GLMM, $n-1$ binary models, where $n$ is number of outcome categories, are fitted. Accordingly, we obtained three binary models, each representing the log odds ratio of a distinctive outcome category, i.e., adaptive automation, inquisitive automation and no automation, over the outcome's reference category, i.e., full automation. As shown in the table, there is no coefficient reported for the last category of each predictor, i.e., predictor's reference category. This can be explained by the structure of the binary models in GLMM, in which predictors are dummy coded as 0 and 1 . For a given predictor, the particularcase of non-reference categories beingall zero is the indicator of reference category being 1 . Hence, additional coefficient for predictor's reference category is redundant.

\begin{tabular}{|c|c|c|c|c|c|c|c|c|c|}
\hline Model & \multirow{2}{*}{\multicolumn{3}{|c|}{$\begin{array}{c}\text { Binary model } 1 \\
\text { Adaptive automation/ } \\
\text { Full automation } \\
\end{array}$}} & \multirow{2}{*}{\multicolumn{3}{|c|}{$\begin{array}{c}\text { Binary model } 2 \\
\text { Inquisitive automation/ } \\
\text { Full automation } \\
\end{array}$}} & \multirow{2}{*}{\multicolumn{3}{|c|}{$\begin{array}{l}\text { Binary model } 3 \\
\text { No automation/ } \\
\text { Full automation } \\
\end{array}$}} \\
\hline Odds ratio & & & & & & & & & \\
\hline Variable & Coefficient & t-value & p-value & Coefficient & t-value & p-value & Coefficient & t-value & p-value \\
\hline $\begin{array}{l}\text { Intercept } \\
\text { Education level }\end{array}$ & 1.169 & 2.116 & $0.035^{* *}$ & 0.058 & 0.092 & 0.926 & -2.301 & -3.055 & $0.002 * *$ \\
\hline Lower than average & -0.612 & -1.659 & $0.098^{*}$ & -0.685 & -1.791 & $0.074^{*}$ & -0.822 & -1.803 & $0.072^{*}$ \\
\hline $\begin{array}{l}\text { Average } \\
\text { Higher than average }^{\mathrm{a}}\end{array}$ & 0.149 & 0.490 & 0.625 & 0.132 & 0.425 & 0.671 & 0.284 & 0.747 & 0.456 \\
\hline Income level & & & & & & & & & \\
\hline Lower than average & -1.820 & -1.701 & $0.089 *$ & 0.430 & 0.902 & 0.368 & 0.226 & 0.414 & 0.679 \\
\hline $\begin{array}{l}\text { Average } \\
\text { Higher than average }{ }^{\text {a }} \\
\text { Agreeableness }\end{array}$ & -0.673 & -4.096 & $0.000 * *$ & -0.081 & -0.168 & 0.867 & 0.129 & 0.228 & 0.820 \\
\hline Lower than average & -0.539 & -0.755 & 0.451 & -0.691 & -0.901 & 0.368 & 1.225 & 1.507 & 0.133 \\
\hline $\begin{array}{l}\text { Average } \\
\text { Higher than average }{ }^{\mathrm{a}} \\
\text { Neuroticism }\end{array}$ & -0.617 & -2.151 & $0.033^{* *}$ & -0.405 & -1.265 & 0.207 & 1.024 & 2.937 & $0.004 * *$ \\
\hline Lower than average & -1.012 & -2.795 & $0.006 * *$ & -1.200 & -3.030 & $0.003 * *$ & -0.886 & -1.916 & $0.056 * *$ \\
\hline $\begin{array}{l}\text { Average } \\
\text { Higher than average }{ }^{a} \\
\text { Openness to experience }\end{array}$ & -0.438 & -1.132 & 0.259 & -1.263 & -3.238 & $0.001 * *$ & -0.803 & -1.633 & 0.103 \\
\hline Lower than average & 0.593 & 0.748 & 0.455 & 1.384 & 1.631 & 0.103 & 2.758 & 3.350 & $0.001 * *$ \\
\hline $\begin{array}{l}\text { Average } \\
\text { Higher than average }^{\text {a }} \\
\text { Context }^{\mathrm{b}}\end{array}$ & -0.031 & -0.106 & 0.915 & 0.297 & 0.988 & 0.324 & 0.889 & 2.515 & $0.012 * *$ \\
\hline Context 1 & 1.627 & 6.636 & $0.000 * *$ & 1.866 & 7.720 & $0.000 * *$ & 0.847 & 2.565 & $0.01 * *$ \\
\hline
\end{tabular}




\begin{tabular}{l|ccc|ccc|ccc} 
Context 2 & 1.489 & 5.831 & $0.000^{* *}$ & 2.069 & 8.093 & $0.000^{* *}$ & 2.394 & 7.915 & $0.000^{* *}$ \\
Context 3 & 1.846 & 4.874 & $0.000^{* *}$ & 0.387 & 1.653 & $0.099^{*}$ & 0.631 & 2.215 & $0.027^{* *}$ \\
Context 4 & 0.604 & 2.574 & $0.01^{* *}$ & 0.378 & 1.651 & $0.099^{*}$ & 0.613 & 2.007 & $0.045^{* *}$ \\
Context 5 $^{\text {a }}$ & & & & & & & & &
\end{tabular}

\section{Table 3-a. Estimated GLMM coefficients and their associated t-values and p-values}

${ }^{\text {a }}$ Predictor's reference Category.

${ }^{\mathrm{b}}$ Context 1: rescheduling an activity (dishwasher), Context 2: rescheduling an activity (washer and dryer), Context 3: managing standby power, Context 4: turning off the unneeded appliances, and Context 5: is turning off the unneeded lights

** Significant terms (p-value $<=0.05$ ).

* Marginally significant terms $(0.05<\mathrm{p}$-value $<0.1)$

\begin{tabular}{|c|c|c|c|c|c|c|c|c|c|}
\hline Model & \multirow{2}{*}{\multicolumn{3}{|c|}{$\begin{array}{c}\text { Binary model } 4 \\
\text { Inquisitive automation/ } \\
\text { Adaptive automation }\end{array}$}} & \multirow{2}{*}{\multicolumn{3}{|c|}{$\begin{array}{c}\text { Binary model } 5 \\
\text { No automation/ } \\
\text { Adaptive automation } \\
\end{array}$}} & \multirow{2}{*}{\multicolumn{3}{|c|}{$\begin{array}{c}\text { Binary model } 6 \\
\text { No automation/ } \\
\text { Inquisitive automation }\end{array}$}} \\
\hline Odds ratio & & & & & & & & & \\
\hline Variable & Coefficient & t-value & p-value & Coefficient & t-value & p-value & Coefficient & t-value & p-value \\
\hline $\begin{array}{l}\text { Intercept } \\
\text { Income level }\end{array}$ & -1.068 & -1.884 & $0.061^{*}$ & -3.418 & -4.406 & $0.000^{* *}$ & -2.554 & -3.255 & $0.001 * *$ \\
\hline Lower than average & 0.887 & 1.962 & $0.051^{*}$ & 0.684 & 1.114 & 0.266 & -0.131 & -0.206 & 0.837 \\
\hline $\begin{array}{l}\text { Average } \\
\text { Higher than average }\end{array}$ & 1.442 & 3.078 & $0.002 * *$ & 1.672 & 2.682 & $0.008 * *$ & 0.310 & 0.483 & 0.630 \\
\hline Agreeableness & & & & & & & & & \\
\hline Lower than average & -0.292 & -0.443 & 0.658 & 1.639 & 2.392 & $0.018 * *$ & 1.755 & 2.692 & $0.008 * *$ \\
\hline $\begin{array}{l}\text { Average } \\
\text { Higher than average }\end{array}$ & 0.121 & 0.417 & 0.677 & 1.566 & 4.565 & $0.000 * *$ & 1.368 & 4.143 & $0.000 * *$ \\
\hline Neuroticism & & & & & & & & & \\
\hline Lower than average & -0.254 & -0.748 & 0.455 & 0.116 & 0.266 & 0.790 & 0.314 & 0.760 & 0.448 \\
\hline $\begin{array}{l}\text { Average } \\
\text { Higher than average }\end{array}$ & -0.757 & -2.100 & $0.037 * *$ & -0.380 & -0.842 & 0.401 & 0.314 & 0.737 & 0.462 \\
\hline Openness to experience & & & & & & & & & \\
\hline Lower than average & 0.639 & 1.046 & 0.296 & 2.025 & 3.113 & $0.002 * *$ & 1.354 & 2.266 & $0.025^{* *}$ \\
\hline $\begin{array}{l}\text { Average } \\
\text { Higher than average }\end{array}$ & 0.315 & 1.180 & 0.239 & 0.956 & 2.847 & $0.005^{* *}$ & 0.700 & 2.166 & $0.031 * *$ \\
\hline Context $^{\mathrm{b}}$ & & & & & & & & & \\
\hline Context 1 & 0.351 & 1.721 & $0.0855^{*}$ & -0.135 & -1.787 & $0.0742 *$ & -0.833 & -2.116 & $0.035 * *$ \\
\hline Context 2 & 0.608 & 2.266 & $0.024 * *$ & 0.951 & 2.644 & $0.008 * *$ & -0.982 & 1.797 & $0.0726 *$ \\
\hline Context 3 & -0.537 & -1.947 & $0.052^{*}$ & -0.262 & -1.687 & $0.092 *$ & 0.245 & 1.649 & $0.099 *$ \\
\hline $\begin{array}{l}\text { Context } 4 \\
\text { Context } 5^{\text {a }}\end{array}$ & -0.165 & 1.691 & $0.0911 *$ & 0.135 & 1.654 & $0.0984 *$ & 0.300 & 1.698 & $0.0898 *$ \\
\hline
\end{tabular}

Table 3-b. Estimated GLMM coefficients and their associated t-values and p-values

412 a Predictor's reference Category.

413 bontext 1: rescheduling an activity (dishwasher), Context 2: rescheduling an activity (washer and dryer), Context 3: managing standby power, Context 4: turning off the unneeded appliances, and Context 5: is turning off the unneeded lights

** Significant terms (p-value $<=0.05$ ).

$416 *$ Marginally significant terms $(0.05<$ p-value $<0.1)$

417

Based on the estimated models (Table 3-a and Table 3-b), following observations are obtained: 
Context variable: The achieved p-values confirm that the effectsfrom context variableare significant (pvalue $<=0.05)$ or marginally significant $(0.05<$ p-value $<0.1)$ in all six binary models. Accordingly, the preference for different automation levels is affected by context in the following ways:

- Full automation: The coefficients in binary models 1,2 and 3for the context variable suggests that, among different context categories, context 5 (i.e., turning off the unneeded lights)has the highest probability of choosing full automation over the other options (i.e., adaptive, inquisitive, and no automation), and context 4 (i.e., turning off the unneeded appliances) comes in the second place in this regard. These observations prove the dominancy of full automation preference in contexts 4 and 5.

- Inquisitive automation: As implied by the coefficients of the context variable in binary models 2,4 and 6 , among different context categories, the probability of preferring inquisitive automation over the other options (i.e., full, adaptive, and no automation) is the highest in context 2 (i.e., rescheduling activity of a dishwasher).Followed by context 2, context 1 (i.e., rescheduling activity of a washer and a dryer) holds the highest probability of choosing inquisitive automation over the other options. Accordingly, inquisitive automation is the dominantly preferred automation level, in context 1 and 2.

- Adaptive automation: The relevant models to assess context's effect on adaptive automation are binary models 1,4 and 5 . As coefficients in these models suggest, among different categories of the context variable, context 3 (i.e., managing standby power) possesses the highest probability of preferring adaptive over the other options (i.e., full, inquisitive, and no automation). In other words, the dominating preference observed for context 3 is adaptive automation.

Education level: The p-values in binary models 1,2, and 3confirm the marginally significant effect $(0.05<$ p-value $<0.1)$ from education level. As the associated coefficients imply, those with lower than average level of education are more willing to prefer full automation over other automation levels compared to the ones with higher than average level of education.

Income level: Based on binary models 1, 3 and 4, those with higher than average level of income are more willing to choose adaptive automation over the other options(i.e. full, inquisitive and no automation) compared to the ones with average income level ( $\mathrm{p}$-value $<=0.05$ ) and lower than average income level $(0.05<$ p-value $<0.1)$.

Agreeableness: The effect from agreeableness is significant in all binary models related to the odds ratio for no automation (binary models 3, 5 and 6).As the coefficients in these models suggest, those with lower levels of agreeableness are more willing to prefer no automation over any kind of automation(i.e., full, adaptive and inquisitive). In other words, agreeableness positively affects preferring any kind of automation over no automation. Also, agreeableness has positive significant effect on preferring adaptive automation over full automation, based on binary model 1.

Neuroticism: For neuroticism, the achieved p-values prove its significant effect in binary models 1,2, 3 and 4 . The negative coefficients for lower than average level of neuroticism in first three stated binary models, which are related to the odds ratio for full automation, show that those low in this trait are more willing to choose full automation over other options (i.e., inquisitive, adaptive and no automation) compared to the ones high in this trait. Also, based on the binary model 4, those high in neuroticism are less willing to choose adaptive automation over inquisitive automation comparedto the ones with average level of neuroticism. 
Openness to experience: Openness to experience has significant effect in binary models 3, 5 and 6, which are all related to the odd ratio for no automation. As coefficients suggest, respondents with lower level of openness to experience are less open to any type of automation. Therefore, as openness to experience decreases, the probability of preferring no automation increases.

470

471

472

473

474

475

476

477

478

479

480

481

482

483

484

485

486

487

488

489

490

491

492

493

494

495

496

497

498

499

500

501

502

503

504

505

506

507

508

509

510

511

\section{DISCUSSION}

Ourfindingsdemonstrate the willingness of occupants to have some level of automation in their homes, as no automation choice appeared to be the least preferred option.This probably emerges from the fact that people have recently gained access to a more matured automation technology in different aspects of their lives and hence, they have more trust on the concept and applications of automation. Despite of the common desire for automation, as suggested by previous studies (e.g., [12, 35]) and also confirmed by our findings, the preferred automation level is not common across the different contexts. As indicated by our results, regardless of the effectsfrom other variables (i.e., demographic and personality related variables), the highest probabilities of preferring full automation, inquisitive automation and adaptive automation are, respectively, associated with the contexts of rescheduling an activity (using a dishwasher or a washer and a dryer), standby power management, and turning off unneeded appliances and lights.

In line with the explanations we previously provided, the major difference between the automation levels suggested in this study is the level of user participation required in the automation process. Accordingly, full automation and adaptive automation are in the region with the higher level of automation than the user participation, as opposed to inquisitive automation, which is in the region with the lower level of automation than user participation. Since automation level should be matched with the function's workload, full automation and adaptive automation are more suitable for the contexts with higher levels of workload, whereas inquisitive automation is more appropriate for the contexts with lower levels of workload.Our findings are in alignment with this argument. Usually, for an average occupant, the use of a dishwasher or a washer and a dryer is not as frequent as use of lights and other appliances that are associated with the contexts of managing standby power and turning off unneeded appliances and lights (due to the relatively low frequency of performing activities of washing the dishes or clothes). Since frequency of a function is an indicator of its workload, for the context of rescheduling an activity of using a dishwasher or a washer and a dryer, due to the relatively lower levels of workload, the choice of inquisitive automation increases occupant control over the automation process without putting an intolerable burden on the occupant. On the other hand, in the contexts of standby power management, and turning off unneeded appliances and lights, due to the higher levels of workload, full automation and adaptive automation are more suitable options.

The main difference between adaptive automation and full automation is the learning capability of the adaptive automation. Accordingly, while in full automation, the automation system operates based on a set of fixed rules, adaptive automation offers flexibility via learning the occupant dynamic patterns, in time. Clearly, all of this flexibility comes with the cost of occasional user participation. Our findings could be an indication of the respondents' desire to accept more workload in exchange of a flexible automation for standby power control, which can learn respondents' dynamic patterns in this context. In contrast, for the context of turning off unneeded appliances and lights, respondents prefer not to accept any workload, probably due to the adequacy of a fixed automation in this context.

Among the demographic-related variables (i.e., age, gender, marital status, education level and income level), our results show that education and income level have marginally significant and significant effects, respectively, on the automation preference.Based on the derived models, as level of education and income increases the probability of preferring adaptive automation increases, whereas, the probability of 
preferring full automation decreases. Considering the known association between higher education and higher income[55],this finding shows that individuals with higher education or income trust more onthe concept of adaptive automation, probably due to satisfactoryprevious experiences; experiences that apparently people with lower education or income levels could not have it because of the lack of access to economicaladaptive automation solutions.

517 Among the personality-related variables (i.e., extraversion, agreeableness, conscientiousness, neuroticism 518 and openness to experience), our results showed the significant effects of agreeableness, neuroticism and openness to experience on the automation preference. Based on our results, both agreeableness and openness to experience have positive effects on preferring any kind of automation (i.e., full, inquisitive and adaptive automation) over no automation. In addition, our results suggest that the respondents with high levels of agreeableness are more willing to choose adaptive automation over full automation. These findings could be explained by the relationship between one's personality and general trust, which impacts human response to non-human agents, such as automation system. Based on previous studies, general trust is positively correlated with the level of agreeableness and openness to experience [56-58]. Accordingly, people with high levels of agreeableness or openness to experience tend to trust more in unfamiliar situations, which motivates them to accept new technologies. Evidence on this argument can befound in studies such as [21] and [59], where, respectively, agreeablenessis shown to have positive effect on accepting mobile commerce and openness to experience is shown to positively affectusing Facebook as a communication tool.Our results also suggest that respondents with higher level of neuroticism are less willing to prefer full and adaptive automation, but more willing to choose inquisitive or no automation. In other words, neuroticism negatively affect preference of the automation levels that are in the region with higher amount of automation than user participation (Figure 1). As individuals high in this trait are prone to negative emotions such as anxiety, they are low in general trust[56-58]. Accordingly, it might be the case that they do not trust on full automation to satisfy their convenience and hence, they want to always have the control over it.

The created models and resulting insights can be used to design an automation system in buildings that better meets userconvenience. Our findingsindicated that automation system in buildings must be adjustable to provide various levels of automation in different contexts and providing a single type of automation to everyone, which is typically the case today, does not seem to be an acceptable solution. In addition, the majority of existing automation solutions (e.g., [30, 60, 61]), particularly for appliance control, do not offer an adequate adaptive automation, meaning that, they mainly provide either full automation or inquisitive automation. However, as suggested by our results, for standby power control of appliances, adaptive automation was associated with the highest probability of being preferred. Therefore, in addition to providing different levels of automation by context, the automation system must be equipped with a learning capability to be able to offer adaptive automation.

\section{LIMITATIONS AND FUTURE WORK}

In this study, we demonstratedhow automation preferences vary by different contexts, personality and demographic characteristics of people. There are limitations associated with our study that require further investigations.A limitation of our work is associated with the fact that we did not explore conflict of preferences in case of shared activities. In other words, respondents provided the responses solely based on their own desires. The stated concern must be considered particularly during the design of an automation system. Meaning that, prior to design, the ownership of appliances must be determined and accordingly appropriate level of automation must be provided based on a mutual agreement. Another limitation iswe considered preference variations by context and did not investigate how preferences might change over time as users get familiar with the automation system.For example, we investigated user's 
automation preferences for rescheduling an activity and for standby power management, however, preference of an occupant, who first preferred inquisitive automation for rescheduling an activity, might change his/her preference to adaptive automation as he/she gains trust to automation after a while. Accordingly, in our future studies we will investigate the effect of time on automation preferences (progressive automation). Specifically, we will design an automation system that is adjustable for providing different levels of automation based on user's desires and accordingly, we will test to see if the pre-experience preferences vary in thereal-world implementations. We will use the findings from this study as a starting point in designing the automation system.

\section{CONCLUSIONS}

In this paper, we investigated occupants' automation preferences in different contexts for lighting system and appliances control in residential buildings. The contexts that we focused in our study include rescheduling an energy consuming activity, activity-based management of different appliance states, and control of lighting systems.For each context, we defined four levels of automation, including full automation, inquisitive automation, adaptive automation and no automation. A survey of 250 respondents was carried out to determine how the automation preferences vary by personality and demographicrelated characteristics, including big five personality traits and age, gender, marital status, education level and income level, respectively, in residential buildings. Due to complexity of the automation concepts, we used descriptive animated videos to explain different concepts to the respondents. In order to analyze the collected data, we carried out descriptive and inferential analysis using statistical techniques. Along this line, we obtained a model using Generalized Linear Mixed Model. Our findings indicated that automation preferences variedby context, such that for rescheduling an activity, inquisitive automation was the most likely preferred option, whereas for managing appliance standby power, adaptive automation was the option with highest probability of being preferred and for turning off the unneeded left on appliances and lights it was full automation. Our findings also indicated that from demographic-related variables education and income levels' effect were, respectively, marginally significant andsignificant on automation preference. From personality traits, agreeableness, neuroticism and openness to experience, were found to be significant. Finally, our investigation showed that in all contexts no automation was the least preferred option.

\section{Acknowledgements}

This material is based upon work supported by the National Science Foundation under grant \# 1351701. Any opinions, findings, and conclusions or recommendations expressed in this material are those of the authors and do not necessarily reflect the views of the National Science Foundation.

\section{References}

[1] Annual Energy Outlook U.S. Energy Information Administration (2015).

[2] S. Wang, Intelligent buildings and building automation, Routledge2009.

[3] F. Mäyrä, A. Soronen, I. Koskinen, K. Kuusela, J. Mikkonen, J. Vanhala, M. Zakrzewski, Probing a proactive home: Challenges in researching and designing everyday smart environments, Human Technology: An Interdisciplinary Journal on Humans in ICT Environments 2(2) (2006) 158-186. [4] M.L. Smith, M.E. Smith, R.R. Gelling, M.L. Cogbill, Method and apparatus for improved building automation, Google Patents, 2001.

[5] R. Parasuraman, T.B. Sheridan, C.D. Wickens, A model for types and levels of human interaction with automation, IEEE Transactions on systems, man, and cybernetics-Part A: Systems and Humans 30(3) (2000) 286-297.

[6] D. Calì, P. Matthes, K. Huchtemann, R. Streblow, D. Müller, CO 2 based occupancy detection algorithm: Experimental analysis and validation for office and residential buildings, Building and Environment 86 (2015) 39-49. 
605

606

607

608

609

610

611

612

613

614

615

616

617

618

619

620

621

622

623

624

625

626

627

628

629

630

631

632

633

634

635

636

637

638

639

640

641

642

643

644

645

646

647

648

649

650

651

652

653

[7] S. Lanzisera, S. Dawson-Haggerty, H.I. Cheung, J. Taneja, D. Culler, R. Brown, Methods for detailed energy data collection of miscellaneous and electronic loads in a commercial office building, Building and Environment 65 (2013) 170-177.

[8] F. Jazizadeh, S. Ahmadi-Karvigh, B. Becerik-Gerber, L. Soibelman, Spatiotemporal lighting load disaggregation using light intensity signal, Energy and Buildings 69 (2014) 572-583.

[9] H.-H. Kim, K.-C. Lee, S. Lee, Location-based human-adaptive air conditioning by measuring physical activity with a non-terminal-based indoor positioning system, Building and Environment 62 (2013) 167173.

[10] A. Ghahramani, C. Tang, B. Becerik-Gerber, An online learning approach for quantifying personalized thermal comfort via adaptive stochastic modeling, Building and Environment 92 (2015) 8696.

[11] S. Ahmadi-Karvigh, B. Becerik-Gerber, L. Soibelman, A framework for allocating personalized appliance-level disaggregated electricity consumption to daily activities, Energy and Buildings 111 (2016) 337-350.

[12] R. Parasuraman, M. Mouloua, B. Hilburn, Adaptive aiding and adaptive task allocation enhance human-machine interaction, Automation technology and human performance: Current research and trends (1999) 119-123.

[13] R. Parasuraman, P.A. Hancock, Adaptive control of mental workload, (2001).

[14] M. Vagia, A.A. Transeth, S.A. Fjerdingen, A literature review on the levels of automation during the years. What are the different taxonomies that have been proposed?, Applied ergonomics 53 (2016) 190202.

[15] J.M. Bradshaw, P.J. Feltovich, H. Jung, S. Kulkarni, W. Taysom, A. Uszok, Dimensions of adjustable autonomy and mixed-initiative interaction, International Workshop on Computational Autonomy, Springer, 2003, pp. 17-39.

[16] J.L. Szalma, G.S. Taylor, Individual differences in response to automation: the five factor model of personality, Journal of Experimental Psychology: Applied 17(2) (2011) 71.

[17] J.B. Rotter, Interpersonal trust, trustworthiness, and gullibility, American psychologist 35(1) (1980) 1.

[18] S.M. Merritt, D.R. Ilgen, Not all trust is created equal: Dispositional and history-based trust in human-automation interactions, Human Factors: The Journal of the Human Factors and Ergonomics Society 50(2) (2008) 194-210.

[19] S.A. Brown, V. Venkatesh, Model of adoption of technology in households: A baseline model test and extension incorporating household life cycle, MIS quarterly (2005) 399-426.

[20] R. Junco, D. Merson, D.W. Salter, The effect of gender, ethnicity, and income on college students' use of communication technologies, Cyberpsychology, Behavior, and Social Networking 13(6) (2010) 619-627.

[21] T. Zhou, Y. Lu, The effects of personality traits on user acceptance of mobile commerce, Intl. Journal of Human-Computer Interaction 27(6) (2011) 545-561.

[22] Residential Energy Consumption Survey (RECS), U.S. Energy Information Administration (2009).

[23] Commercial buildings energy consumption survey (CBECS), U.S. Energy Information

Administration (2012).

[24] J. Wong, H. Li, Development of a conceptual model for the selection of intelligent building systems, Building and Environment 41(8) (2006) 1106-1123.

[25] A. Ghahramani, G. Castro, B. Becerik-Gerber, X. Yu, Infrared thermography of human face for monitoring thermoregulation performance and estimating personal thermal comfort, Building and Environment 109 (2016) 1-11.

[26] B. Meerbeek, C. de Bakker, Y. de Kort, E. van Loenen, T. Bergman, Automated blinds with light feedback to increase occupant satisfaction and energy saving, Building and Environment 103 (2016) 7085. 
[27] B. Meerbeek, M. te Kulve, T. Gritti, M. Aarts, E. van Loenen, E. Aarts, Building automation and perceived control: A field study on motorized exterior blinds in Dutch offices, Building and Environment 79 (2014) 66-77.

[28] A. Brush, B. Lee, R. Mahajan, S. Agarwal, S. Saroiu, C. Dixon, Home automation in the wild: challenges and opportunities, Proceedings of the SIGCHI Conference on Human Factors in Computing Systems, ACM, 2011, pp. 2115-2124.

[29] S. Davidoff, M.K. Lee, C. Yiu, J. Zimmerman, A.K. Dey, Principles of smart home control, International Conference on Ubiquitous Computing, Springer, 2006, pp. 19-34.

[30] L. Hamill, Controlling smart devices in the home, The Information Society 22(4) (2006) 241-249. [31] M. Tambe, P. Scerri, D.V. Pynadath, Adjustable autonomy for the real world, Journal of Artificial Intelligence Research 17(1) (2002) 171-228.

[32] C.I. Penaloza, Y. Mae, F.F. Cuellar, M. Kojima, T. Arai, Brain machine interface system automation considering user preferences and error perception feedback, IEEE Transactions on Automation Science and Engineering 11(4) (2014) 1275-1281.

[33] J.-y. Kwak, P. Varakantham, R. Maheswaran, M. Tambe, F. Jazizadeh, G. Kavulya, L. Klein, B. Becerik-Gerber, T. Hayes, W. Wood, SAVES: A sustainable multiagent application to conserve building energy considering occupants, Proceedings of the 11th International Conference on Autonomous Agents and Multiagent Systems-Volume 1, International Foundation for Autonomous Agents and Multiagent Systems, 2012, pp. 21-28.

[34] A.T. Alan, S.D. Ramchurn, T. Rodden, E. Costanza, J. Fischer, N.R. Jennings, Managing energy tariffs with agents: a field study of a future smart energy system at home, Adjunct Proceedings of the 2015 ACM International Joint Conference on Pervasive and Ubiquitous Computing and Proceedings of the 2015 ACM International Symposium on Wearable Computers, ACM, 2015, pp. 1551-1558. [35] M. Ball, V. Callaghan, Introducing Intelligent Environments, Agents and Autonomy to Users, Intelligent Environments (IE), 2011 7th International Conference on, IEEE, 2011, pp. 382-385. [36] C. Röcker, M.D. Janse, N. Portolan, N. Streitz, User requirements for intelligent home environments: a scenario-driven approach and empirical cross-cultural study, Proceedings of the 2005 joint conference on Smart objects and ambient intelligence: innovative context-aware services: usages and technologies, ACM, 2005, pp. 111-116.

[37] D. Bonino, F. Corno, L. De Russis, Home energy consumption feedback: A user survey, Energy and Buildings 47 (2012) 383-393.

[38] S. Karjalainen, Consumer preferences for feedback on household electricity consumption, Energy and Buildings 43(2) (2011) 458-467.

[39] Ö. Göçer, Y. Hua, K. Göçer, Completing the missing link in building design process: Enhancing post-occupancy evaluation method for effective feedback for building performance, Building and Environment 89 (2015) 14-27. [40] L. Bakker, E. Hoes-van Oeffelen, R. Loonen, J. Hensen, User satisfaction and interaction with automated dynamic facades: A pilot study, Building and Environment 78 (2014) 44-52.

[41] S. Karjalainen, Should it be automatic or manual-The occupant's perspective on the design of domestic control systems, Energy and Buildings 65 (2013) 119-126.

[42] O.P. John, E.M. Donahue, R.L. Kentle, The big five inventory-versions 4a and 54, Berkeley, CA: University of California, Berkeley, Institute of Personality and Social Research, 1991.

[43] G.R. Newsham, B.G. Bowker, The effect of utility time-varying pricing and load control strategies on residential summer peak electricity use: a review, Energy Policy 38(7) (2010) 3289-3296.

[44] A. Faruqui, S. Sergici, Household response to dynamic pricing of electricity: a survey of 15 experiments, Journal of regulatory Economics 38(2) (2010) 193-225.

[45] S. Power, Laerence berkeley national laboratory, United State Available at $<$ http://standby. lbl. gov (2015).

[46] I. Georgievski, T.A. Nguyen, M. Aiello, Combining activity recognition and AI planning for energysaving offices, Ubiquitous Intelligence and Computing, 2013 IEEE 10th International Conference on and 
10th International Conference on Autonomic and Trusted Computing (UIC/ATC), IEEE, 2013, pp. 238245.

[47] V. Garg, N. Bansal, Smart occupancy sensors to reduce energy consumption, Energy and Buildings 32(1) (2000) 81-87.

[48] M. Buhrmester, T. Kwang, S.D. Gosling, Amazon's Mechanical Turk a new source of inexpensive, yet high-quality, data?, Perspectives on psychological science 6(1) (2011) 3-5.

[49] J.E. Barlett, J.W. Kotrlik, C.C. Higgins, Organizational research: Determining appropriate sample size in survey research, Information technology, learning, and performance journal 19(1) (2001) 43.

[50] T.F. Jaeger, Categorical data analysis: Away from ANOVAs (transformation or not) and towards logit mixed models, Journal of memory and language 59(4) (2008) 434-446.

[51] H.J. Seltman, Experimental design and analysis, Online at: http://www. stat. cmu. edu/, hseltman/309/Book/Book. pdf (2012).

[52] G. Verbeke, G. Molenberghs, Linear mixed models for longitudinal data, Springer Science \& Business Media2009.

[53] A. Zuur, E. Ieno, N. Walker, A. Saveliev, G. Smith, Mixed effects models and extensions in ecology with R. Gail M, Krickeberg K, Samet JM, Tsiatis A, Wong W, editors, New York, NY: Spring Science and Business Media (2009).

[54] J. Sauro, J.R. Lewis, Quantifying the user experience: Practical statistics for user research, Elsevier2012.

[55] E. Diener, E. Sandvik, L. Seidlitz, M. Diener, The relationship between income and subjective wellbeing: Relative or absolute?, Social Indicators Research 28(3) (1993) 195-223.

[56] L.L. Couch, J.M. Adams, W.H. Jones, The assessment of trust orientation, Journal of personality assessment 67(2) (1996) 305-323.

[57] T. Mooradian, B. Renzl, K. Matzler, Who trusts? Personality, trust and knowledge sharing, Management learning 37(4) (2006) 523-540.

[58] A.M. Evans, W. Revelle, Survey and behavioral measurements of interpersonal trust, Journal of Research in Personality 42(6) (2008) 1585-1593.

[59] Y. Amichai-Hamburger, G. Vinitzky, Social network use and personality, Computers in human behavior 26(6) (2010) 1289-1295.

[60] B.L. Thomas, D.J. Cook, CARL: activity-aware automation for energy efficiency, Proceedings of the 2014 ACM International Joint Conference on Pervasive and Ubiquitous Computing: Adjunct Publication, ACM, 2014, pp. 939-946.

[61] V. Singhvi, A. Krause, C. Guestrin, J.H. Garrett Jr, H.S. Matthews, Intelligent light control using sensor networks, Proceedings of the 3rd international conference on Embedded networked sensor systems, ACM, 2005, pp. 218-229. 